\title{
EL ESTADO Y LOS DERECHOS HUMANOS EN LA NUEVA CONSTITUCIÓN POLÍTICA DEL ESTADO PLURINAGIONAL DE BOLIVIA*
}

\section{THE STATE AND THE HUMAN RIGHTS IN THE NEW POLITICAL CONSTITUTION OF THE PLURINATIONAL STATE OF BOLIVIA}

\author{
Mauro BENENTE**
}

RESUMEN: En el presente trabajo analizo el modo en que Álvaro García Linera conceptualiza la transición del Estado boliviano, y muestro cómo la nueva Constitución Política se inscribe en ese proceso. Desde la perspectiva de la gubernamentalidad marco que en la Constitución hay una nueva racionalidad de gobierno que avanza hacia la plurinacionalidad y abandona el neoliberalismo, pero la racionalidad que subyace al diagrama de los derechos humanos se mantiene en un registro eminentemente liberal.

Palabras clave: Estado, gubernamentalidad, derechos humanos, liberalismo.
ABSTRACT: In this paper I analyze how Álvaro Garcia Linera conceptualizes the transition of the Bolivian State, and I show how the New Political Constitution is part of that process. From the viewpoint of governmentality I argue that the Constitution has a new rationality of government witch advances to plurinationality and leaves the neoliberalism, but the rationality that underlies the diagram of human rights retains a predominantly liberal record.

Keyzerds: State, governmentality, human rights, liberalism.

* Artículo recibido el 4 de abril de 2016 y aceptado para su publicación el 14 de septiembre de 2016.

** Doctor en derecho (Universidad de Buenos Aires). Becario posdoctoral del Consejo Nacional de Investigaciones Científicas y Técnicas. Investigador en el Instituto de Investigaciones Jurídicas y Sociales A. L. Gioja. Profesor adjunto (int.) a cargo del curso "Michel Foucault, el derecho y el poder" en la Facultad de Derecho de la UBA, y profesor titular ordinario de filosofía del derecho en la Universidad Nacional de José C. Paz. maurobenente@ yahoo.com.

Boletín Mexicano de Derecho Comparado nueva serie, año XLX, núm. 148, enero-abril de 2017, pp. 49-79.

D. R. (C) 2017. UNAM, Instituto de Investigaciones Jurídicas. 
SUMARIO: I. Introducción. II. La perspectiva de la gubernamentalidad. III. El Estado en transición. La lectura de García Linera. IV. La Nueva Constitución Politica del Estado. V. Notas finales. VI. Bibliografia.

\section{INTRODUCGIÓN}

El proceso político boliviano de los últimos quince años se ha transformado en un centro de atención para las ciencias sociales. Las manifestaciones en repudio a las políticas neoliberales, el resurgimiento de los movimientos indígenas y campesinos, el ascenso de Evo Morales a la presidencia y la consolidación del Movimiento Al Socialismo en diferentes procesos electorales, la Nueva Constitución Política del Estado Plurinacional, son algunos de los acontecimientos que motivan numerosos e interesantes estudios.

En este trabajo me interesa dar cuenta de la transición del Estado boliviano tal como la describe Álvaro García Linera, desarrollo que resulta interesante no solamente por sus lúcidos análisis inscritos en el marxismo, sino porque en la medida en que se trata de reflexiones del vicepresidente del Estado plurinacional, estamos frente a una mirada del proceso analizado a su mejor luz. Luego de realizar esta exposición, me interesará inscribir a la Nueva Constitución Política vigente desde 2009 en esa transición estatal, mostrando cómo subyace una lógica para avanzar hacia un Estado plurinacional, y también interventor en el mercado. Sin embargo, desde la perspectiva de la gubernamentalidad, me sostendré que si bien se han reflexionado y se han implementado nuevas formas estatales, la racionalidad que estructura los derechos se mantiene en un registro eminentemente liberal.

\section{LA PERSPECTIVA DE LA GUBERNAMENTALIDAD}

Quizá uno de los grandes aportes de Michel Foucault ha sido evitar realizar una teoría del poder, haber preferido desplegar analíticas más frágiles y de corto alcance espacio-temporal. Sin embargo, una constante que aparece en sus investigaciones es dejar de concebir al Estado como foco y centro que explica el funcionamiento de las relaciones de poder. Una de las premisas que han guiado sus investigaciones propone estudiar al "poder fuera del 
Esta revista forma parte del acervo de la Biblioteca Jurídica Virtual del Instituto de Investigaciones Jurídicas de la UNAM

modelo del Leviatán, fuera del campo delimitado por la soberanía jurídica y la institución del Estado".

En el marco de esta lógica de analizar las relaciones de poder más allá de los límites del Estado² debe inscribirse la noción de gubernamentalidad, que supone no tomar al Estado como el punto de partida que explica el funcionamiento de las lógicas de gobierno, sino que propone inscribirlo dentro del perímetro más amplio del gobierno de los hombres: "el Estado no es más que una peripecia del gobierno y no es el gobierno un instrumento del Estado". ${ }^{3}$ Para Foucault, hay que evitar desarrollar "una teoría del Estado, como podemos y debemos ahorrarnos una comida indigesta", ${ }^{4}$ lo que implica no iniciar los análisis por la naturaleza y las funciones del Estado, no tenerlo como un universal político, no centrar su atención sobre él, sino sobre el gobierno. ${ }^{5}$ Esto es así porque "el Estado no es un universal, el Estado no es en sí mismo una fuente autónoma de poder", ${ }^{6}$ sino que es la resultante de estatizaciones que son modificadas, desplazadas, y transformadas: el Estado es el "efecto móvil de un régimen de gubernamentalidades múltiples".?

Los estudios que parten de la perspectiva de la gubernamentalidad no abordan solamente las prácticas de gobierno, sino fundamentalmente sus racionalidades, que pueden ser distintas y entrar en competencia en un mismo contexto histórico. ${ }^{8}$ La gubernamentalidad alude a un tipo de ejercicio de poder o de conducción de conductas que se encuentra guiada

1 Foucault, Michel, "Il faut défendre la société", Cours au Collège de France (1975-1976), París, Gallimard-Seuil, 1997, p. 30.

2 Mills, Sara, Michel Foucault, Londres, Routledge, 2003, p. 49.

3 Foucault, Michel, Sécurité, territoire, population. Cours au Collège de France (1977-1978), París, Gallimard-Seuil, 2004, p. 253.

4 Foucault, Michel, Naissance de la biopolitique. Cours au Collège de France (1978-1979), Paris, Gallimard-Seuil, 2004, p. 79.

5 Valverde, Mariana y Levi, Ron, "Gobernando la comunidad a través de la comunidad", Delito y Sociedad. Revista de Ciencias Sociales, Buenos Aires, Santa Fe, núm. 22, 2006, p. 8.

6 Foucault, Michel, op. cit., nota 4, p. 73.

7 Idem.

8 Es importante aclarar que esta noción de racionalidad no tiene "un gran valor normativo, asociado a una «Razón» en mayúsculas y en singular, sino que tiene un significado meramente relativo a determinadas prácticas históricas". De Marinis, Pablo, "Gobierno, gubernamentalidad, Foucault y los anglofoucaultianos $(\mathrm{O}$ un ensayo sobre la racionalidad política del neoliberalismo)", en Ramos Torre, Ramón y García Salgas, Fernando (eds.), Globalización, riesgo, reflexividad, Madrid, Centro de Investigaciones Sociológicas, 1999, p. 88. 
Esta revista forma parte del acervo de la Biblioteca Jurídica Virtual del Instituto de Investigaciones Jurídicas de la UNAM

por una racionalidad y una práctica reflexiva, ${ }^{9}$ y el foco de atención se encuentra "en el conocimiento ideal de los planes de gobierno, más que en los detalles acerca de cómo se implementan y cuáles son los efectos que podrían tener empíricamente". ${ }^{10}$ Es por ello que puede decirse que el problema planteado "es el de la racionalidad del gobierno, es decir, la manera en la cual es gobierno reflexiona su práctica". ${ }^{11}$

En línea con lo anterior, es posible distinguir entre racionalidades, programas y tecnologías de gobierno. La racionalidad gubernamental alude a "un modo o sistema de pensamiento sobre la naturaleza de la práctica de gobierno (quién puede gobernar; qué es gobernar; qué o quién es gobernado), capaz de hacer, de algún modo, esta actividad pensable y practicable, tanto por sus operadores como por sobre quienes es practicada". ${ }^{12}$ La racionalidad gubernamental o arte de gobernar alude a "la manera reflexiva de gobernar mejor y también, y al mismo tiempo, la reflexión sobre la mejor manera posible de gobernar", ${ }^{13}$ y no se inscribe únicamente en el registro de la teoría ni en la filosofía política, sino que tiene una clara dimensión práctica. ${ }^{14}$ Por su lado, los programas de gobierno funcionan como una "traducción" de las racionalidades políticas y logran un ajuste entre lo que es deseable y lo que puede llegar a ser posible - en el marco

9 Hindess, Barry, "Liberalism, Socialism and Democracy: Variations on a Governmental Theme", en Barry, Andrew et al. (eds.), Foucault and Political Reason. Liberalism, NeoLiberalism and Rationalities of Government, Chicago, Chicago University Press, 1996, p. 106; Lemke, Thomas, "Foucault, Governmentality, and Critique", Rethinking Marxism: A fournal of Economics, Culture E̊ Society, vol. 14, núm. 3, 2002, p. 53; Rose, Nikolas, Powers of Freedom. Reframing Political Thought, Cambridge, Cambridge University Press, 1999, p. 7.

10 O'Malley, Pat, "Experimentos en gobierno. Analíticas gubernamentales y conocimiento estratégico del riesgo", Revista Argentina de Sociología, Buenos Aires, núm. 8, 2007, p. 155 .

11 Gros, Frédéric, Michel Foucault, Paris, Presses Universitaires de France, 1996, p. 85. En definitiva, lo que se encuentra en el trasfondo de estos estudios es la suposición según la cual "es posible analizar la racionalidad política, así como se puede analizar cualquier racionalidad científica". Foucault, Michel, 2001, "La technologie politique des individus", Dits et écrits II, Paris, Gallimard, núm. 364, 2001, p. 1646.

12 Gordon, Collin, "Governmental Rationality: An Introduction”, en Burchell, Graham et al. (eds.), The Foucault Effect. Studies in Governmentality, Chicago, Chicago University Press, 1991, p. 4.

13 Foucault, Michel, op. cit., nota 4, p. 4.

14 Dean, Mitchell, Governmentality. Power and Rule in Modern Society, Londres, Sage, 1999, p. 18.

D. R. C 2017. UNAM, Instituto de Investigaciones Jurídicas, Boletín Mexicano de Derecho Comparado, núm. 148, pp. 49-79. 
Esta revista forma parte del acervo de la Biblioteca Jurídica Virtual del Instituto de Investigaciones Jurídicas de la UNAM

de las luchas sociales -.${ }^{15}$ Finalmente, las tecnologías gubernamentales son las encargadas de instrumentar, a partir de diferentes procedimientos y técnicas, las racionalidades y los programas de gobierno. ${ }^{16}$

La perspectiva de la gubernamentalidad focaliza particularmente sobre las racionalidades gubernamentales, dentro de las cuales hay que inscribir al Estado, sus formas institucionales, sus programas y tecnologías. Pero también, y tal como veremos, dentro de las racionalidades gubernamentales se inscribe la consagración de derechos, que no deben tenerse solamente como límites ajenos a las prácticas de gobierno, sino como integrantes de ellas: se trata de límites al Estado que se inscriben en una determinada racionalidad gubernamental. Teniendo esto en cuenta, me interesa marcar cómo la transición estatal que vive Bolivia, y en particular el diseño que propone la Nueva Constitución Política del Estado, supone una nueva racionalidad de gobierno, que avanza hacia una plurinacionalidad y abandona progresivamente el neoliberalismo. Sin embargo, esta nueva racionalidad se fractura, deja de ser nueva, al momento de establecer el diagrama de derechos.

\section{El ESTAdo EN TRANSICIÓN. LA LEGTURA DE GARCíA LiNERA}

En varios de sus trabajos, Álvaro García Linera postula que hay que conceptualizar al Estado a partir de tres dimensiones: a) material, relativa a sus instituciones; $b$ ) ideal, que alude al conjunto de creencias, valores y percepciones; $c$ ) correlación de fuerzas, jerarquía en la conducción y control de las decisiones. ${ }^{17}$ A partir de estas tres dimensiones puede observarse al Estado

15 Rose, Nikolas y Miller, Peter, "Political Power beyond the State: Problematics of Government”, The British Fournal of Sociology, Londres, vol. 43, núm. 2, 1992.

16 Son los "mecanismos a través de los cuales diversos tipos de autoridades han tratado de dar forma, normalizar e instrumentalizar la conducta, el pensamiento, las decisiones y las aspiraciones de los otros, en vistas de alcanzar los objetivos que ellas consideran deseables". Rose, Nikolas y Miller, Peter, "Governing Economic Life", Economy and Society, vol. 19, núm. 1, 1990, p. 8.

17 García Linera, Álvaro, "Lucha por el poder en Bolivia”, La potencia plebeya, Bogotá, Siglo del Hombre Editores-Clacso, 2009, p. 452; conferencia "La construcción del Estado", Buenos Aires, Facultad de Ciencias Sociales de la Universidad de Buenos Aires, 2010, p. 4; "El Estado en transición. Bloque de poder y punto de bifurcación", en García Linera, Álvaro et al., El Estado. Campo de lucha, La Paz, Muela del Diablo- Comuna-Clacso, 2010, pp. 8 y 9. 
como una "construcción política de monopolios legítimos sobre determinados recursos escasos de la sociedad: coerción, recursos económicos públicos y legitimación". ${ }^{18}$ De todos modos García Linera no se propone analizar al Estado en los momentos de estabilidad, sino en los de transición, "en momentos en que se construye una nueva estructura estatal". ${ }^{19}$ En los tiempos de estabilidad, estas tres dimensiones mantienen o presenten fisuras en sus componentes internos, y por ello los cambios y las mutaciones son relativamente previsibles. De modo contrario, en los momentos de crisis cada una de estas dimensiones "presentan ámbitos de antagonismo recurrente, inestabilidad e incertidumbre estratégica en cuanto a su funcionamiento". ${ }^{20}$

García Linera realiza su teorización del Estado en transición a partir de la experiencia boliviana, que divide en una serie de etapas: $a$. Develación de la crisis, $b$. Empate catastrófico, $c$. Sustitución de las elites, $d$. Construcción, reconversión o restitución conflictiva de un bloque de poder económico-político-simbólico, $c$.- $d$. Capacidad de movilización convertida en presencia estatal gubernamental, e. Punto de bifurcación, $f$. Emergencia de las contradicciones creativas.

a) La develación de la crisis se produce cuando el sistema político y simbólico que lograba constituir una "tolerancia o hasta acompañamiento moral de los dominados hacia las clases dominantes, se quiebra parcialmente". ${ }^{21}$ Se abre un espacio en el cual emerge un bloque social y políticamente disidente con una importante capacidad de movilización y expansión territorial, que comienza a ganar aceptación en diferentes sectores y no logra ser canalizado por el Estado. "22 Esto sucedió en Bolivia entre 2000 y 2003, un periodo iniciado con la "Guerra del Agua" (1999-2000) y continuado con

18 García Linera, Álvaro, "El Estado en transición. Bloque de poder y punto de bifurcación”, en García Linera, Álvaro et al., El Estado. Campo de lucha, La Paz, Muela del Diablo- Comuna-Clacso, 2010, p. 9.

19 Ibidem, p. 7.

20 Ibidem, p. 31.

21 Ibidem, p. 12.

22 Aquí puede advertirse una resonancia gramsciana, porque en definitiva García Linera está mostrando cómo la clase subalterna "puede e incluso debe ser dirigente aun antes de conquistar el poder gubernamental". Gramsci, Antonio, "El problema de la dirección política en la formación y desarrollo de la nación y del Estado moderno en Italia”, Cuadernos de la Cárcel 5, México, Ediciones Era-Benemérita Universidad Autónoma de Puebla, 1975, p. 387. 
Esta revista forma parte del acervo de la Biblioteca Jurídica Virtual del Instituto de Investigaciones Jurídicas de la UNAM

otras notables manifestaciones, entre las que se encuentra la "Guerra del Gas”, que culminó con la renuncia de Gonzalo Sánchez de Lozada. ${ }^{23}$ De todos modos, ésta es solamente una dimensión de la crisis, una crisis de los componentes de corta duración del Estado, en este caso del modelo neoliberal que comienza a desarrollarse desde mediados de la década de $1980 .{ }^{24}$ Sin embargo, también se hizo presente una crisis de los componentes de larga duración del Estado, que se manifestó con la "fisura colonial del Estado" que se vincula con "la presencia de los actores sociopolíticos más influyentes del país, que son básicamente los indígenas"—, ${ }^{25}$ y la "fisura espacial del Estado" - que se relaciona con "el traslado de los ejes decisorios económicopolíticos del Estado, de una región (norte-occidental) a otra (oriental)"—. ${ }^{26}$

b) El empate catastrófico es un momento en el cual la articulación de las demandas populares comienza a disputar la autoridad política, estableciendo mecanismos alternativos de legitimidad y toma de decisiones. Un empate catastrófico emerge cuando "no existe la capacidad de una hegemonía completa, sino de una confrontación irresuelta por esa hegemonía entre dos protohegemonías". ${ }^{27}$ Estamos frente a un conflicto generalizado por la redistribución del poder del Estado, pero "lo característico de esta pugna por el poder es que ninguno de los bloques tiene la capacidad de imponerse sobre el otro". ${ }^{28}$ En Bolivia se produjo entre 2003 y 2005, cuando en paralelo y superposición al Parlamento existían asambleas donde se

23 García Linera, Álvaro, conferencia "La construcción del Estado", Buenos Aires, Facultad de Ciencias Sociales de la Universidad de Buenos Aires, pp. 6-8. Lo más importante de la Guerra del Agua "fue saber que el régimen neoliberal era débil, que se lo podía derrotar". García Linera, Álvaro, Las tensiones creativas de la revolución. La quinta fase del proceso de cambio, La Paz, Vicepresidencia del Estado Plurinacional, 2011, p. 13.

24 García Linera, Álvaro, "Lucha por el poder en Bolivia", La potencia plebeya, Bogotá, Siglo del Hombre Editores-Clacso, 2005, pp. 452-455.

25 Ibidem, p. 456. "Hoy en día, los movimientos sociales más impactantes son o están dirigidos por indios, son fuerzas indígenas... Los indios nunca habían tenido tanta posibilidad de presión y de contra-poder como lo estamos viendo hoy. No cabe duda de que son los sujetos fundamentales de la actual interpelación al Estado". Idem.

26 Ibidem, p. 463. Este traslado territorial de los focos de poder se explica por la pérdida de peso dentro de la economía boliviana de zonas mineras como Oruro, o de ciudades como La Paz, y el crecimiento de Santa Cruz como polo agroindustrial. García Linera, Álvaro, Las tensiones creativas de la revolución. La quinta fase del proceso de cambio, La Paz, Vicepresidencia del Estado Plurinacional, 2011 , p. 14.

27 García Linera, Álvaro, op. cit., nota 24, p. 475.

28 Idem. 
tomaban decisiones políticas que disputaban el monopolio de la coerción estatal. Por un lado había un proyecto que seguía apostando a una economía liberal y la monoculturalidad del Estado, y por otro, un proyecto que bregaba más intervención del Estado en la economía, intentaba recuperar la dinámica económica de las comunidades, la multiculturalidad y la presencia indígena en los espacios de toma de decisiones.

c) La sustitución de las elites alude al proceso por el cual los sectores sociales movilizados van ocupando los espacios de gobierno, algo que en Bolivia comienza a suceder con la primera presidencia de Evo Morales, iniciada el 22 de enero de 2006. Este nuevo bloque político "asume la responsabilidad de convertir las demandas contestatarias en hechos estatales desde el gobierno". ${ }^{29} \mathrm{El}$ nuevo bloque está integrado por campesinos e indígenas con una base material de pequeñas producciones agrícolas y urbanas, pero también por profesionales e intelectuales vinculados con construcciones políticas de izquierda, el sindicalismo y los movimientos vecinales. Este nuevo bloque ha creado interesantes mecanismos de conducción del Estado: $a$. la base de las políticas públicas se encuentra en las decisiones adoptadas organizaciones sociales; $b$. la presencia directa de representantes de las organizaciones sociales en diferentes niveles del aparato estatal; $c$. el lento ingreso de una nueva intelectualidad al Estado. ${ }^{30}$ La creación de estos mecanismos de conducción del Estado implica que no estamos frente a "una simple mutación de elites en el poder, sino una auténtica sustitución de la composición de clase del poder del Estado". ${ }^{31}$

d) La construcción, reconversión o restitución conflictiva de un bloque de poder económico-político-simbólico alude a un intento de "ensamblar el ideario de la sociedad movilizada con la utilización de recursos materiales del o desde el Estado". ${ }^{32}$

c-d) En El Estado en transición, García Linera alude a la "sustitución de elites" y a la "Construcción, reconversión o restitución conflictiva de un bloque de poder económico-político-simbólico" como dos momentos separados, mientras que en "La construcción del Estado" el segundo parece estar incluido en el primero. Por su lado, en Las tensiones creativas de la revolución estos dos momentos están subsumidos bajo la denominada capacidad

\footnotetext{
29 García Linera, Álvaro, op. cit., nota 19, p. 13.

30 Ibidem, p. 19.

31 Idem.

32 Idem.
}

D. R. (C) 2017. UNAM, Instituto de Investigaciones Jurídicas, Boletín Mexicano de Derecho Comparado, núm. 148, pp. 49-79. 
Esta revista forma parte del acervo de la Biblioteca Jurídica Virtual del Instituto de Investigaciones Jurídicas de la UNAM

de movilización convertida en presencia estatal gubernamental. Este proceso implica una radicalización del empate catastrófico, puesto que estamos en presencia de un gobierno efectivamente controlado por las clases populares, pero con un poder de Estado - su lógica y su mando institucional - todavía en manos de las clases históricamente dominantes. Sin embargo, no se trata solamente de una radicalización, sino que también tiene una notable particularidad: "este «empate» se inscribe en la propia institucionalidad dinámica del Estado". 33

e) Punto de bifurcación es un concepto que García Linera retoma de Ilya Prigogine; en otros trabajos lo describe como el "momento jacobino de la revolución", ${ }^{34}$ y aplicado a la transición estatal presenta tres características: a) el diálogo se suspende y hay una manifestación no necesariamente violenta de las fuerzas sociales en pugna; $b$ ) una de las fuerzas o bloques asume el mando; c) la política se convierte en la continuación de la guerra por otros medios y no a la inversa. ${ }^{35} \mathrm{El}$ punto de bifurcación marca que la situación política "se dirime en base al despliegue de correlación de fuerzas sin mediación alguna: fuerzas materiales, simbólicas y económicas". ${ }^{36}$ Es el tiempo "de la confrontación desnuda o de la medición de fuerzas desnuda de la sociedad, donde callan los procesos de construcción de legitimidad, de consenso, y donde la política se define como un hecho de fuerza". ${ }^{37}$ Como salida a este proceso se reconstituye el bloque de poder conservador o se consolida uno nuevo. Esta situación se desarrolló en Bolivia entre agosto y octubre de 2008 cuando la derecha intentó deshacerse del presidente Evo Morales primero a través del referéndum revocatorio del 10 de agosto - en el cual Evo obtuvo 67.43\% en su favor-, y luego con diferentes intentos desestabilizadores, a los que el gobierno respondió con movilizaciones sociales, acciones articuladas con las fuerzas armadas, y logrando que en octubre de 2008 se aprobara el nuevo texto

33 García Linera, Álvaro, Las tensiones creativas de la revolución. La quinta fase del proceso de cambio, La Paz, Vicepresidencia del Estado Plurinacional, 201 1, p. 18.

34 Idem.

35 Aquí García Linera dice parafrasear a Foucault, pero ésta no es una conceptualización foucaulteana, sino que el autor francés se limita a realizar una genealogía de aquellos discursos histórico-políticos que presentan a la política como la guerra continuada por otros medios. Foucault, Michel, "Il faut défendre la société", Cours au Collège de France (19751976), París, Gallimard-Seuil, 1997.

36 García Linera, Álvaro, op. cit., nota 19, p. 34.

37 García Linera, Álvaro, op. cit., nota 29, p. 11. 
Esta revista forma parte del acervo de la Biblioteca Jurídica Virtual del Instituto de Investigaciones Jurídicas de la UNAM

constitucional..$^{38}$ Además, tres procesos electorales fueron confirmando este ciclo: el 25 enero de 2009 por referéndum se aprobó la nueva Constitución con el $61.43 \%$ de votos favorables; en diciembre de 2009, Evo Morales fue reelecto con el 64\%, y el 4 de abril de 2010 el MAS logró el control de dos tercios de los municipios y de más de dos tercios de las gobernaciones.

f) En 2011, con la publicación de Las tensiones creativas de la revolución, García Linera comienza a aludir a estos momentos como "fases" del proceso revolucionario boliviano, ${ }^{39}$ y agrega una nueva etapa: la emergencia de las contradicciones creativas. Existen dos tipos de tensiones o contradicciones: a) las fundamentales y antagónicas, que dividen estructuralmente a la sociedad; $b$ ) las secundarias, que se pueden superar con métodos democráticos y revolucionarios. El momento de las contradicciones creativas es un ejemplo de estas contradicciones secundarias, en las que no hay tensiones entre bloques de poder antagónicos, sino que ellas existen al interior del bloque popular que protagoniza el proceso de cambio. ${ }^{40}$ En la experiencia boliviana es posible encontrar cuatro tensiones creativas, y la primera de ellas refiere a la relación entre el Estado y los movimientos sociales. ${ }^{41}$ El Estado supone una concentración de las decisiones, un monopolio de la coerción y de la administración de lo público-estatal, mientras que los movimientos sociales se caracterizan por una constante socialización, deliberación y definición democrática de las decisiones. Es por ello que el "[g]obierno de movimientos sociales es por tanto una tensión creativa, dialéctica, productiva y necesaria entre concentración y descentralización de decisiones". ${ }^{42}$ El gobierno de los movimientos sociales convive con la tensión entre concentración y descentralización, entre tiempos cortos para lograr resultados y tiempos largos de deliberación. No obstante, esta

\footnotetext{
38 García Linera, Álvaro, op. cit., nota 19, p. 39.

39 García Linera, Álvaro, op. cit., nota 33, p. 12.

40 García Linera, Álvaro, op. cit., nota 26, p. 24.

41 García Linera identifica otras tensiones: a) la flexibilidad hegemónica frente a la firmeza en el núcleo social, que alude a la necesidad de ampliar el proceso revolucionario e incorporar distintos sectores sociales, pero simultáneamente mantener la conducción indígena, popular, obrera y campesina del proceso; b) entre intereses generales e intereses particulares y privados; c) entre la necesidad de industrialización y la del vivir bien. Al tratarse de tensiones que se producen al interior del bloque de popular, García Linera no proyecta sobre ellas una mirada negativa, sino que asume que son vivificantes y que su "existencia y tratamiento democrático y revolucionario nos permitirán avanzar”. Ibidem, p. 72.
}

42 Ibidem, p. 28. 
Esta revista forma parte del acervo de la Biblioteca Jurídica Virtual del Instituto de Investigaciones Jurídicas de la UNAM

tensión puede resolverse con el denominado Estado integral, que supone que "el Estado (el centro de decisiones) comienza a disolverse en un proceso largo en la propia sociedad, y donde esta última empieza a apropiarse, cada vez más, de los procesos de decisión del Estado". ${ }^{43}$

Finalmente, las últimas conceptualizaciones sobre la transición del Estado se leen en Geopolitica de la Amazonía, un trabajo publicado en 2012 al calor del conflicto del TIPNIS. Allí aludía a la existencia de un proceso revolucionario que emergiendo de los movimientos sociales "ha afectado y atravesado la propia estructura estatal, modificando la misma naturaleza de la sociedad civil". ${ }^{44}$ Se trata de una revolución política que supone la participación de los indígenas en el Estado y la consagración de derechos de los pueblos indígenas, y una revolución económica que ha modificado radicalmente la propiedad y la utilización de la riqueza social. Pero además es una revolución político-cultural, porque la presencia indígena en los espacios de decisión es consecuencia de la acción de los movimientos sociales y organizaciones sindicales, indígenas y campesinas. La presencia del mundo indígena-popular en la conducción del Estado no es una simple ocupación de lugares de toma de decisión, sino una "transformación orgánica de la propia institucionalidad estatal mediante la presencia de estructuras organizativas del mundo indígena-popular en la trama decisional y deliberativa del Estado". ${ }^{45}$

43 Ibidem, p. 29. De todos modos este proceso no es sencillo no solamente porque depende de una constante lucha, sino porque en ciertos momentos puede llevar a una paradoja: a) la apropiación que los movimientos sociales hacen del Estado amenaza con disolverlos, $b$ ) pero si ellos no se apropian del Estado, éste queda reducido una situación de apariencia, de parcialidad colonial que beneficia solamente a unos pocos - recobrando entonces los movimientos una mayor presencia y potencia-. Ibidem, pp. 34 y 35.

44 García Linera, Álvaro, Geopolítica de la Amazonía. Poder hacendal-patrimonial y acumulación capitalista, La Paz, Vicepresidencia del Estado Plurinacional, 2012, p. 8. Sobre el caso específico de la Amazonia boliviana, donde el Estado se ha autonomizado del bloque dominante territorial y ha avanzado en un proceso de destrucción del latifundio y la distribución de tierras y riquezas, postula que "el Estado no solo condensa la nueva correlación de fuerzas político-económicas de la sociedad emergente, de las luchas sociales exitosas, sino que además deviene en sujeto material e institucional que ayuda a promover nuevas movilizaciones sociales que transformen las estructuras de dominación aun presentes en determinadas regiones y esferas de la sociedad". Ibidem, p. 52.

45 Ibidem, p. 9. Además, agrega que "[a]sí como en los últimos 100 años el mundo popular construyó la ciudadanía de derechos a través del sindicato... ahora la toma del poder estatal por los movimientos sociales es una toma sindical del poder del Estado". Ibidem, p. 8. 
Esta revista forma parte del acervo de la Biblioteca Jurídica Virtual del Instituto de Investigaciones Jurídicas de la UNAM

Según entiendo, los desarrollos de García Linera son especialmente relevantes, al menos por dos razones. Por un lado, porque se inscriben dentro de una tradición marxista que marca que en el momento transicional que supone la toma del Estado por parte de los sectores subalternos es necesario avanzar en reformas estructurales del aparato estatal. De este modo, teorizando sobre la experiencia de la Comuna de París, en el "Manifiesto del Consejo General de la Asociación Internacional de los Trabajadores" - escrito en mayo de 1871- Marx sostuvo que "la clase obrera no puede limitarse simplemente a tomar posesión de la máquina del Estado tal y como está servirse de ella para sus propios fines". ${ }^{46}$ En los 71 días de funcionamiento del gobierno comunal en París, que para Engels representó un ejemplo concreto de la dictadura del proletariado, ${ }^{47} \mathrm{se}$ suprimió el ejército, se declararon electivos y revocables todos los cargos, y con sueldos equivalentes al de los obreros. Es teniendo esto en cuenta que en el prefacio del Manifiesto Comunista, del 24 de junio de 1872, Marx y Engels expresaban que las medidas revolucionarias que se enumeraban en el segundo capítulo de la edición original de 1848 debían ser redactadas nuevamente, en parte porque la experiencia de la Comuna había demostrado que la clase obrera no se puede limitar a tomar la maquinaria estatal y servirse de ella para realizar sus intereses. ${ }^{48}$

Esta necesidad de transformar las estructuras estatales se encuentra no solamente en las líneas más clásicas del marxismo, sino también en

46 Marx, Karl, La guerra civil en Francia, Madrid, Fundación Federico Engels, 2007, p. 64.

47 Engels, Friedrich, "Introducción", en Marx, Karl, La guerra civil en Francia, Madrid, Fundación Federico Engels, 2007, p. 22.

48 Marx, Karl y Engels, Friedrich, "Prefacio a la edición alemana de 1872", en Manifiesto Comunista, Madrid, Debate, 1998, p. 98. Tomando como base estas lecturas, Lenin consideraba que los trabajadores necesitaban del Estado para reprimir las posibles resistencias de la burguesía, acabar con la explotación, y poner en marcha una economía socialista, pero aclaraba que el proletariado debía transformar al Estado, y por eso la supresión el ejército y la elegibilidad y revocabilidad de todos los funcionarios representaba "un caso de «transformación de la cantidad en calidad»: la democracia, llevada a la práctica del modo más completo y consecuente que puede concebirse, se convierte de democracia burguesa en democracia proletaria, de un Estado (fuerza especial de represión de una determinada clase) en algo que ya no es una Estado propiamente dicho". Lenin, Vladimir I., El Estado y la revolución, Madrid, Fundación Federico Engels, 2009, p. 65. Es por estas transformaciones - y por el horizonte de un futuro sin dominación política- que Lenin aludía a un proceso de "transición del Estado al no Estado" o a la existencia ya no de un Estado, sino de un "semiestado proletario". Ibidem, pp. 40 y 78. 
Esta revista forma parte del acervo de la Biblioteca Jurídica Virtual del Instituto de Investigaciones Jurídicas de la UNAM

las propuestas de un socialismo democrático - que no deben confundirse con una vía parlamentaria al socialismo -.${ }^{49}$ En este orden de ideas, Nicos Poulantzas proponía que el objetivo del socialismo no debía ser destruir al Estado ${ }^{50}$ sino desarrollar poderosas transformaciones para avanzar en una democracia representativa radicalizada, pero articulada con prácticas de democracia directa, el desafío era

...emprender una transformación radical del Estado articulando la ampliación y la profundización de las instituciones de la democracia representativa y de las libertades (que fueron también una conquista de las masas populares) con el despliegue de las formas de democracia directa de base y el enjambre de los focos autogestionarios. ${ }^{51}$

Con aires de familia, y para la misma época, Ralph Miliband insistía en la necesidad de reformar profundamente las estructuras estatales, ${ }^{52}$ y por ello indicaba que la oposición entre reformismo y vía violenta al socialismo no era una dicotomía correctamente planteada.$^{53} \mathrm{El}$ objetivo es establecer mecanismos de interrelación entre las estructuras gubernamentales y las organizaciones de la sociedad civil, para lo cual hay que diseñar una "red flexible y compleja de órganos de participación popular que operen en toda la sociedad civil y cuyo objetivo no sea reemplazar al Estado sino complementarlo". ${ }^{44}$ Esto exige profundas reformas en las estructuras y en el personal del Estado, la creación de órganos de participación popular y entonces la "estrategia «reformista», al menos así entendida, puede producir una combinación entre dirección y democracia suficientemente eficaz para mantener a raya a las fuerzas conservadoras y crear las condiciones que permitan avanzar en un proceso de transición". ${ }^{55}$

49 Poulantzas, Nicos, L'État, le pouvoir, le socialisme, Paris, Presses Universitaires de France, 1978, pp. 286 y 287.

50 Ibidem, p. 289.

51 Ibidem, p. 283.

52 Miliband, Ralph, Marxismo y politica, Madrid, Siglo XXI, 1978, pp. 223 y 224.

53 Es así que "un acceso constitucional al poder podría ir seguido de una remodelación total de las instituciones estatales y una toma de poder no implica necesariamente tal remodelación. Es más, como lo que se intenta es extender el poder popular, una transición pacífica podría ser más favorable a ese proyecto que una violenta". Ibidem, p. 225.

$54 \quad$ Ibidem, p. 238.

55 Ibidem, p. 239. 
En sus últimos trabajos, García Linera rescata enfáticamente el aporte del socialismo democrático y su doble movimiento de democratizar a las instituciones representativas y de ampliar los espacios de democracia directa. ${ }^{56}$ En este plano, es importante aclarar que desde esta perspectiva la noción de democracia aparece como un concepto en disputa con el liberalismo, puesto que alude a un conjunto de instituciones y principios, pero también a una gestión común de aquello que es común: "hay democracia si en lo común que tenemos los ciudadanos participamos" ${ }^{\text {"57 }}$ si se desarrolla "una gestión común de los recursos comunes: instituciones, derechos y riquezas" ${ }^{58}$ En vistas de analizar el grado de avance hacia un socialismo democrático, García Linera distingue entre los nudos principales, los decisivos, y los estructurales. Si solamente se revolucionan los principales, dentro de los cuales están el gobierno, el parlamento y los medios de comunicación, estamos frente a renovaciones del sistema político dentro de un mismo orden estatal. Si además de los nudos principales se transforman los decisivos, en los que se encuentran la organización de los sectores subalternos, la participación en la gestión de los bienes comunes, el uso de los recursos públicos, y las ideas con las cuales los individuos se movilizan, estamos frente a revoluciones democráticas que renuevan el orden capitalista "bajo formas de ampliación democratizada de sus instituciones y derechos". ${ }^{59}$ Finalmente, si además de los principales y decisivos mutan los estructurales, que comprenden las formas de propiedad y gestión de las fuentes de riqueza en la perspectiva de su comunitarización y también los esquemas morales mediante las cuales las personas actúan en el mundo en vistas de desmontar los monopolios en la gestión de los bienes comunes, "nos encontramos ante revoluciones sociales que inician un largo proceso de transformación estatal, un nuevo bloque de clases dirigente, y una democratización creciente de la política y de la economía". ${ }^{60}$

Según entiendo, García Linera trabaja intelectual y políticamente en la construcción de una nueva racionalidad de gobierno, que entre otras

56 García Linera, Álvaro, "Estado, democracia y socialismo", en Socialismo comunitario. Un horizonte de época, La Paz, Vicepresidencia del Estado Plurinacional, 2015, pp. 64 y 65.

57 García Linera, Álvaro, "A la izquierda europea", en Socialismo comunitario. Un horizonte de época, La Paz, Vicepresidencia del Estado Plurinacional, 2015, p. 23.

58 Idem.

59 García Linera, Álvaro, op. cit., nota 56, p. 64.

60 Idem.

D. R. (C) 2017. UNAM, Instituto de Investigaciones Jurídicas, Boletín Mexicano de Derecho Comparado, núm. 148, pp. 49-79. 
variables necesita de crear nuevas formas de Estado. Pero además, sus reflexiones son importantes - e insisto en este punto - porque estamos frente a quien, en tanto vicepresidente del Estado Plurinacional, es un actor principal del proceso. Es por ello que se trata de un intelectual que está leyendo el proceso de avance hacia una nueva racionalidad gubernamental a su mejor luz, mostrando todas sus fortalezas y ocultando sus posibles debilidades, enfatizando sobre la radicalidad de las modificaciones y la excelencia de los resultados, y morigerando las continuidades con la racionalidad de gobierno del pasado. Estamos en presencia de un autor que está leyendo a su mejor luz las reformas estatales exigidas desde las tradiciones marxistas en vistas de avanzar hacia una nueva racionalidad gubernamental.

Es también realizando una lectura que maximice sus fortalezas como puede decirse que la Nueva Constitución Política del Estado vigente desde 2009 se inscribe en este proceso de transformaciones estatales inspiradas en una nueva racionalidad. Lo notable es que esta necesidad de reformar las estructuras del Estado no se replica en una urgencia por reformar la estructura de los derechos. En los desarrollos de García Linera se encuentra un potente esfuerzo por marcar las transiciones estatales que atraviesa Bolivia y que se direccionan hacia una racionalidad gubernamental distinta y distante del liberalismo y del neoliberalismo. Algo similar se encuentra en una parte del texto constitucional, en donde numerosas disposiciones marcan una discontinuidad con el liberalismo y el neoliberalismo. Sin embargo, estas novedades se fracturan en el diagrama de los derechos, que mantienen una racionalidad liberal.

\section{La Nueva Constitución Política del Estado}

\section{Las nuevas estructuras del Estado}

La Nueva Constitución Política se presenta a sí misma marcando una ruptura con el Estado colonial y neoliberal, y es así que en el preámbulo narra: "dejamos en el pasado el Estado colonial, republicano y neoliberal. Asumimos el reto histórico de construir colectivamente el Estado Unitario Social de Derecho Plurinacional Comunitario, que integra y articula los propósitos de avanzar hacia una Bolivia democrática, productiva, portadora e inspiradora de la paz, comprometida con el desarrollo integral y con la 
Esta revista forma parte del acervo de la Biblioteca Jurídica Virtual del Instituto de Investigaciones Jurídicas de la UNAM

libre determinación de los pueblos". Esta mirada sobre el pasado que deja atrás la Constitución también se hizo presente en el discurso pronunciado por el presidente Evo Morales en ocasión de su promulgación:

...después de 500 años de rebelión, invasión y el saqueo permanente; después de 180 años de resistencia contra un Estado colonial, después de 20 años de lucha permanente contra un modelo neoliberal, hoy 7 de febrero de 2009, es un acontecimiento histórico, un acontecimiento inédito, singular para Bolivia y para Latinoamérica, reunido acá para promulgar la nueva Constitución Política del Estado. ${ }^{61}$

Leído en la clave de la gubernamentalidad, el proceso de transición dentro del cual se inscribe la Nueva Constitución intenta diagramar una nueva racionalidad gubernamental que busca terminar con las racionalidades neoliberales y coloniales. Aunque avanzar hacia esta nueva racionalidad no se limita a reformas estatales ni mucho menos a una reforma constitucional, me interesa marcar qué huellas de estas rupturas pueden encontrarse en el denominado constitucionalismo transformador que se está desplegando en el Estado Plurinacional de Bolivia. ${ }^{62}$

El proceso hacia una racionalidad plurinacional que incluye, pero también excede las transformaciones estatales, se encuentra abierto, depende y dependerá de las correlaciones de fuerzas; no se reduce a lo que estipula la Constitución, pero aun así en parte de sus disposiciones se advierte una lógica de avance hacia la plurinacionalidad. El texto constitucional asume que la "diversidad cultural constituye la base esencial del Estado Plurinacional Comunitario" (artículo 98), reconoce como idiomas oficiales el castellano y los de 36 naciones y pueblos indígenas y campesinos, teniendo el Estado y los departamentos que utilizar el castellano y al menos uno de los restantes (artículo 5o.). El Estado adopta una forma de gobierno de democracia representativa y participativa, pero además

61 Morales Ayma, Evo, "Palabras del presidente del Estado Plurinacional de Bolivia, Evo Morales Ayma, en la promulgación de la nueva Constitución Política del Estado”, en Enciclopedia Histórica Documental del Proceso Constituyente Boliviano, La Paz, Vicepresidencia del Estado Plurinacional, 2012, p. 8.

62 Sousa Santos, Boaventura de, Refundación del Estado en América Latina, Lima, Instituto Internacional de Derecho y Sociedad-Programa Democracia y Transformación Global, 2010, pp. 71-80; 2012, "Refundación del Estado en Bolivia", en AA. VV., Pensando el mundo desde Bolivia, La Paz, Vicepresidencia del Estado Plurinacional, 2012, p. 123. 
Esta revista forma parte del acervo de la Biblioteca Jurídica Virtual del Instituto de Investigaciones Jurídicas de la UNAM

comunitaria (artículo 11, inc. 3), se organiza territorialmente en departamentos, provincias, municipios, y también en territorios indígena originario campesinos (artículo 269), a los que se les garantiza un régimen de autonomía (artículos 289-296). ${ }^{63}$ Se consagra a los pueblos indígenas campesinos el derecho a una educación intercultural (artículo 78), a su identidad cultural, a la libre determinación y territorialidad, y a la titulación colectiva de tierras (artículo 30). También reconoce, protege y promueve la organización económica comunitaria (artículo 317). El Estado reconoce la propiedad comunitaria o colectiva de las comunidades indígenas y campesinas, que se considera indivisible, imprescriptible, inembargable, inalienable e irreversible, y no está sujeta al pago de impuestos a la propiedad agraria (artículo 394), y se adjudica a las comunidades indígenas originarias campesinas la titularidad de la gestión de las áreas forestales que se encuentren en su territorio (artículo 388).

La Nueva Constitución Política del Estado incluye la revocatoria de mandatos (artículo 240), la iniciativa y la consulta popular de leyes (artículos 11 y 162); pero una de las más interesantes novedades en el rediseño de los poderes clásicos del constitucionalismo se encuentra en las modificaciones del Poder Judicial. En este plano, y dentro de la racionalidad plurinacional, se establece una igual jerarquía entre la justicia ordinaria y la justicia indígena originaria campesina (artículo 179, inc. 2), que aunque ejerce su competencia con autoridades, valores y procedimientos propios (artículo 191, inc. 2), debe respetar los derechos y garantías de la Constitución (artículo 191, inc. 1). ${ }^{64}$ También se modificaron otras instituciones del Poder Judicial históricamente diseñadas como contramayoritarias (Gargarella, 1996), puesto que se estipuló que las magistradas y magistrados del Tribunal Constitucional Plurinacional, del Tribunal Supremo de Justicia, del Tribunal Agroambiental y del Consejo de la Magistratura sean elegidos por sufragio universal - previa preselección de la Asamblea Legislativa Plurinacional-, duren seis años en sus funciones y no puedan

63 Buena parte del régimen de autonomía indígena originaria campesina se encuentra regulada en la Ley Marco de Autonomías y Descentralización (Ley 31, artículos 42-48), promulgada el 19 de julio de 2010.

64 La competencia de la justicia indígena originaria campesina y de la justicia ordinaria se regularon con la Ley 73, del 29 de diciembre de 2010, que establece límites de vigencia material de la justicia indígena (artículo 10.II) y le impone el respeto de ciertos principios y derechos (artículos 5o. y 6o.). 
Esta revista forma parte del acervo de la Biblioteca Jurídica Virtual del Instituto de Investigaciones Jurídicas de la UNAM

ser reelectos inmediatamente (artículos 182, 183, 188, 194, 198 y 200). ${ }^{65}$ En particular, el Tribunal Constitucional Plurinacional está integrado por siete magistradas o magistrados, y al menos dos "provendrán del sistema indígena originario campesino, por auto-identificación personal” (artículo 13, inc. 2, ley 27).

Si en vistas de avanzar en dirección de una racionalidad plurinacional el Estado debe asumir formas distintas a las hasta ese entonces existentes, para dejar atrás al neoliberalismo son necesarias nuevas vinculaciones entre el Estado y el mercado. Entre el avance hacia una plurinacionalidad y el abandono del neoliberalismo hay puntos de conexión, puesto que, a modo de ejemplo, un nuevo ordenamiento territorial que reconozca la propiedad comunal indígena marca una ruptura con la privatización de los bienes comunes propia del neoliberalismo. Sin embargo, al menos analíticamente, es posible encontrar en la Constitución disposiciones directamente introducidas para salirse de las lógicas neoliberales que imperaron en América Latina. Existen varios artículos que distan de una lógica liberal que apela al libre mercado sin intervención estatal, y de una lógica neoliberal que exige una intervención del Estado para garantizar el funcionamiento de la competencia. ${ }^{66}$

Esta nueva racionalidad de gobierno marca la necesidad de limitar el accionar de prácticas de gobierno desarrolladas no por el Estado, sino por agentes económicos, por poderes no estatales. Es así que además de estipular que la propiedad debe tener una función social y no debe ser contraria el interés colectivo (artículos 56, 393), ${ }^{67}$ prohíbe los monopolios

65 Además de estos artículos de la Constitución, la normativa electoral que rige las elecciones de magistrados y magistradas se condensa en la Ley 18 del Órgano Electoral Plurinacional y en la Ley 26 del Régimen Electoral, y lo relativo al Tribunal Constitucional Plurinacional se regula en la Ley 27.

66 Hayek, Friedrich, Camino de servidumbre, Madrid, Alianza, 2011, pp. 64-67.

67 En el capítulo IX, dedicado a la "Tierra y el territorio", el artículo 397 aclara que "II. La función social se entenderá como el aprovechamiento sustentable de la tierra por parte de pueblos y comunidades indígena originario campesinos, así como el que se realiza en pequeñas propiedades, y constituye la fuente de subsistencia y de bienestar y desarrollo sociocultural de sus titulares. En el cumplimiento de la función social se reconocen las normas propias de las comunidades. III. La función económica social debe entenderse como el empleo sustentable de la tierra en el desarrollo de actividades productivas, conforme a su capacidad de uso mayor, en beneficio de la sociedad, del interés colectivo y de su propietario. La propiedad empresarial está sujeta a revisión de acuerdo con la ley, para verificar el cumplimiento de la función económica y social". 
Esta revista forma parte del acervo de la Biblioteca Jurídica Virtual del Instituto de Investigaciones Jurídicas de la UNAM

y oligopolios en la producción y comercialización de bienes y servicios (artículo 314) y en los medios de comunicación (artículo 117), y rechaza el latifundio (artículo 398 b y ss.). ${ }^{68}$ La organización económica debe generar trabajo digno y contribuir a la reducción de la desigualdad y la erradicación de la pobreza, fortalecer la soberanía económica del país, impidiéndose la acumulación privada de poder económico que haga peligrar esa soberanía (artículo 312). En vistas de combatir la pobreza y la indigencia, la organización económica debe apuntar a una distribución y redistribución justa de la riqueza y del excedente, aminorar las desigualdades en el acceso a los recursos productivos, y reducir las desigualdades regionales (artículo 313). Asimismo, el Estado debe promover las formas cooperativas sin fines de lucro (artículo 310), priorizar la inversión boliviana frente a la extranjera, quedando esta última sometida a la jurisdicción, a las leyes y a las autoridades bolivianas (artículo 320). Además, debe proteger a las organizaciones económicas campesinas, las asociaciones de pequeños productores urbanos, y la producción artesanal con identidad cultural (artículo 334), y por ello, en las compras que realice el Estado las pequeñas empresas y las organizaciones económicas de pequeños productores deben gozar de preferencias (artículo 334).

En términos generales el Estado debe intervenir en toda la cadena productiva de los sectores estratégicos y garantizar su abastecimiento para preservar la calidad de vida de los habitantes (artículo 311); pero son notablemente más precisas las regulaciones sobre los denominados recursos naturales. Es así que el Estado asume el control de la explotación, industrialización, transporte y comercialización de los recursos naturales, y si se asocia con privados, éstos deben reinvertir sus utilidades (artículo 351). La gestión y la administración de estos recursos debe garantizar el control y la participación social (artículo 351), y la explotación estará sujeta a un proceso de consulta a la población afectada (artículo 352). La exploración, explotación, refinación, industrialización, transporte y comercialización de recursos naturales no renovables tienen el carácter de necesidad estatal y utilidad pública (artículo 356), y se prohíbe la apropiación privada de los

68 En consonancia con esto último, luego que el 21 de diciembre del 2010 se dictara la Ley de Derechos de la Madre Tierra (Ley 71), el 15 de octubre de 2012 se sancionó la Ley Marco de la Madre Tierra y Desarrollo Integral para el Buen Vivir (Ley 300), que insiste en que para disminuir las desigualdades que existen en el acceso a la tierra, agua, bosques, biodiversidad, el Estado Plurinacional debe eliminar el latifundio (artículo 19.2). 
recursos hídricos (artículo 357). Además, sólo el Estado puede explotar y comercializar hidrocarburos (artículo 359), y si empresas extranjeras participan en la cadena productiva, se consideran inválidas las prórrogas de jurisdicción (artículo 366). Finalmente, es el Estado el responsable de las riquezas minerales, y ejerce funciones de control sobre la cadena productiva de minería (artículo 369).

Si bien la ruptura con la racionalidad neoliberal de gobierno no puede reducirse a una serie de artículos constitucionales, al menos en este plano se advierte una interesante discontinuidad con el constitucionalismo liberal y neoliberal. Ya no estamos frente a limitaciones hacia el Estado en vistas de proteger la libre circulación de mercancías ni ante un paradigma que apunta la intervención del Estado en vistas de garantizar la competencia. Sin embargo, en el plano de los derechos encuentro notorias, y quizá preocupantes, continuidades. El constitucionalismo posliberal y posneoliberal del Estado Plurinacional se fractura en el diagrama de derechos y mantiene una racionalidad fundamentalmente liberal.

\section{Las mismas estructuras de los derechos. La racionalidad liberal}

Una buena parte del constitucionalismo de los siglos XVIII y XIX, además de responder a intereses políticos y económicos concretos, se ha inspirado en ciertas ideas liberales, y aquí me interesa remarcar cómo Foucault conceptualiza al liberalismo en los términos de una racionalidad gubernamental específica, para luego analizar la estructura de los derechos de la Nueva Constitución.

En los siglos XVII y XVIII los juristas plantearon a los derechos naturales como anteriores al soberano, y por ello como límites al accionar del Estado. Desde el derecho se construyó un límite al Estado, pero exterior, lo que significaba que: a) provenía de una voluntad divina u origen remoto; $b$ ) tenía la función de construir límites que si eran avasallados el gobierno se transformaba en ilegítimo. ${ }^{69}$ Frente a esta limitación externa los economistas construyeron una limitación interna, que implicaba que: 1) era una regulación no de derecho, sino de hecho, por lo que si el gobierno avasallaba ese límite no se transformaba en ilegítimo, sino en torpe; 2) establecía una distinción entre las acciones que convenían y no

69 Foucault, Michel, op. cit., nota 4, pp. 10-12. 
Esta revista forma parte del acervo de la Biblioteca Jurídica Virtual del Instituto de Investigaciones Jurídicas de la UNAM

convenían realizar; 3) no se construía por fuera de los objetivos del gobierno, sino que era "uno de los medios, y quizás el medio fundamental, de alcanzar precisamente esos objetivos". ${ }^{70}$

Es muy importante tener presente que no estamos frente a una ausencia de racionalidades y tecnologías gubernamentales, sino ante un refinamiento de ellas, guiadas por un principio bien novedoso: una limitación que se inscribe dentro de la propia práctica gubernamental. El liberalismo no se debe concebir únicamente como simple doctrina o teoría económica ni como el discurso ideológico de una burguesía con pretensiones de dominación, ${ }^{71}$ sino fundamentalmente como "un principio y un método de racionalización del ejercicio del gobierno", ${ }^{72}$ cuyo principal problema y objetivo es ponerle límites. ${ }^{73}$ En este orden, la libertad no debe ser tenida solamente como un límite al poder, sino que se constituye como un elemento estrictamente necesario de la racionalidad liberal de gobierno: sólo se puede gobernar correctamente a condición que un "determinado número de formas de libertad, sean respetadas. No respetar la libertad no es solamente ejercer abusos de derecho en relación a la ley, sino que es sobre todo no saber gobernar como se debe". ${ }^{74}$

Sobre las características de estas libertades que se erigen como límites al gobierno, y cuyo respeto son la clave del éxito de las acciones gubernamentales, Foucault se muestra dubitativo. En algunos pasajes indica que la libertad "es mucho más la espontaneidad, la mecánica interna e intrínseca de los procesos económicos, que una libertad jurídica reconocida como tal a los individuos". ${ }^{75}$ Ella no refiere a aquello que

70 Ibidem, p. 13. Esta mirada implica un notable aporte para repensar los vínculos entre economía y política, que se resuelven a partir de "técnicas y dispositivos que no provienen ni de la política ni de la economía". Lazzarato, Maurizio, Biopolítica. Estrategias de gestión y agenciamientos de creación, Bogotá, Universidad Central-IESCO-Se Cauto, 2007, p. 66. La manera en la cual se disuelve esta tensión no es ni a partir de la racionalidad política ni de la económica, sino de "una racionalidad exterior a ellas y que Foucault denomina «el gobierno de los hombres», o sea las técnicas de gobierno". Idem.

71 Malette, Sébastien, La gouvernementalité chez Michel Foucault, Québec, Université Laval, 2006, p. 87.

72 Castro, Edgardo, "Categorías de la filosofía política contemporánea: gubernamentalidad y soberanía”, Revista de Filosofía y Teoría Política, La Plata, núm. 35, 2004, p. 14.

73 Hindess, Barry, Discourses of Power: From Hobbes to Foucault, Oxford, Blackwell, 1996, p. 67.

74 Foucault, Michel, op. cit., nota 3, p. 361.

75 Foucault, Michel, op. cit., nota 4, p. 63. 
puede realizarse por no estar prohibido ni a derechos inalienables, sino que es "positivamente requerida como el necesario correlato e instrumento de gobierno cuya tarea es asegurar el óptimo funcionamiento de los procesos naturales". ${ }^{76}$ Sin embargo, en otros pasajes no alude a un naturalismo, sino a una libertad que tiene que ser organizada, incluso con coacciones. Ella no es un universal sobre la que pesan variaciones, consumaciones o amputaciones, sino que es "una relación actual entre gobernantes y gobernados", ${ }^{77}$ y lo propio del liberalismo es que necesita de la libertad, pero no como una libertad innata, sino como una libertad que se debe producir y organizar. Esta situación parece implicar una paradoja, puesto que "[p] or un lado hay que producir libertad, pero ese mismo gesto implica que, por otro lado, se establecen limitaciones, controles, coerciones, obligaciones apoyadas en amenazas". ${ }^{78}$

Si bien creo que la separación entre juristas y economistas tendría que ser morigerada, y que la distinción entre una libertad natural y otra fabricada debería ser atenuada, porque incluso asumiendo su naturalidad es menester una reglamentación, entiendo que lo más estimulante es el modo de concebir la racionalidad propia del liberalismo: para desarrollar satisfactoriamente las prácticas de gobierno es menester limitar el poder del Estado. Bajo esta racionalidad, el constitucionalismo liberalconservador de los siglos XVIII y XIX ha estructurado a los derechos como límites al poder el Estado. La racionalidad liberal-conservadora del constitucionalismo clásico no se expresó solamente en el modo de diagramar el Poder Legislativo, Ejecutivo y Judicial, sino en la estructuración de derechos, puesto que éstos forman parte de una racionalidad gubernamental. De acuerdo con esta racionalidad, en la medida en que el poder se concentra exclusivamente en el Estado, los derechos se estructuran como límites a sus acciones, pero esta limitación no opera por fuera, sino dentro de la propia racionalidad de gobierno. Sin embargo, estas protecciones de esferas de libertad necesitan de regulaciones desarrolladas y exigibles al Estado. La racionalidad liberal de los derechos se incluye dentro de la propia racionalidad gubernamental, y tiene la par-

76 Burchell, Graham, "Peculiar Interests: Civil Society and Governing the System of Natural Liberty", en Burchell, Graham et al. (eds.), The Foucault Effect. Studies in Governmentality, Chicago, Chicago University Press, 1991, p. 139.

77 Foucault, Michel, op. cit., nota 4, p. 64.

78 Ibidem, p. 65. 
ticularidad de establecer exigencias o limitaciones solamente respecto del poder del Estado.

Teniendo en cuenta esta inclusión del diagrama de derechos dentro de la propia racionalidad de gobierno, creo que es posible sostener que la racionalidad gubernamental que subyace al proceso de cambio en el Estado Plurinacional de Bolivia se encuentra fracturada. Si leemos el modo en que García Linera describe y conceptualiza el proceso, y si tomamos la Nueva Constitución Política del Estado, creo que estamos frente a una racionalidad distinta que la enarbolada por el liberalismo, puesto que se establece la necesidad de limitar el accionar de los poderes no estatales, en particular poderes económicos. Para desarrollar una nueva forma de gobernar, la racionalidad liberal que reduce el poder al poder del Estado fue reemplazada por una nueva racionalidad que reconoce, y por ello también limita, el poder de poderes no estatales. Esto implica una interesante y estimulante novedad en la racionalidad que está supuesta en la tradición del constitucionalismo; pero esta novedad se fractura en el diagrama de los derechos humanos, que se mantienen como límites (o como exigencias) del poder del Estado, aunque no respecto de otros poderes no estatales.

Con excepción de algunos referidos a la niñez y la adolescencia (artículos 60 y 64), y una inespecífica referencia al deber de la sociedad de proteger el sistema educativo y luchar contra el analfabetismo (artículos 77-84), en la Nueva Constitución Política los derechos se plantean como límites o exigencias solamente del poder del Estado, aunque no de los otros poderes. Esta formulación de los derechos humanos como límites o exigencias únicamente respecto del poder del Estado no representa una variable que resultó fallida en la formulación jurídica, en la redacción del texto constitucional, sino que se encuentra en el núcleo de la racionalidad que ha guiado el diagrama de los derechos en la Asamblea Constituyente. Para desarrollar su labor, la Asamblea se dividió en veintiún comisiones, una de las cuales debía abordar la temática de los "Deberes, derechos y garantías". La comisión, que se separó en una subcomisión de "Derechos y Garantías" y otra de "Deberes", elaboró un "Informe de mayoría" suscrito por los cinco constituyentes que representaban al "Movimiento al Socialismo" (MAS) y el constituyente del "Movimiento Originario Popular", y un "Informe de minoría" suscrito por los tres representantes del "Poder Democrático y Social". 
Quienes redactaron el "Informe de mayoría" entendieron que la Constitución marcaba una ruptura con el pasado colonial y neoliberal, y representaba el intento de construir un nuevo orden social y político: la Asamblea Constituyente constituía "la expresión del agotamiento de un modelo económico, social y político estructural e históricamente excluyente, elitista y arbitrario que colmó la desesperanza del pueblo boliviano". ${ }^{79}$ De todos modos, el diagnóstico sobre el modelo socioeconómico no vale solamente para el caso boliviano, sino para gran parte del continente:

[c]asi en todos los países de América Latina han fracasado las reformas estructurales de carácter neoliberal, cuyos supuestos logros macroeconómicos, privatizaciones y liberalización no se han reflejado en el mejoramiento efectivo de las condiciones de vida, reducción de la pobreza, la exclusión y marginalidad de grandes sectores de la población. ${ }^{80}$

Teniendo en cuenta este panorama es que los representantes del MAS postularon que era urgente avanzar en la "reconfiguración de un nuevo modelo social, político y económico del país". ${ }^{81}$

Además de una mirada general sobre el contexto sociopolítico, el informe incluye un diagnóstico sobre la situación de los derechos humanos, reconociéndose que en las últimas décadas del siglo XX la comunidad internacional había avanzado en la consagración de un gran catálogo de derechos, pero su vigencia todavía era una tarea pendiente. En particular, sobre los derechos económicos sociales y culturales (DESG) se lee que

...la alteración en la aplicación de los recursos económicos, sociales y culturales se refleja en el debilitamiento y desmantelamiento del Estado de Bienestar. La evidente debilidad conceptual y normativa de estos Derechos, considerados de realización progresiva, los convierte en carentes de exigibilidad inmediata y efectiva, pues su cumplimiento depende de la disponibilidad del Estado. ${ }^{82}$

79 "Informe de mayoría de la Comisión de Deberes, Derechos y Garantías", 2012, en Enciclopedia Histórica Documental del Proceso Constituyente Boliviano, vol. III, La Paz, Vicepresidencia del Estado Plurinacional, p. 359.

80 Ibidem, p. 361.

81 Idem.

82 Ibidem, p. 360. Las itálicas me pertenecen. 
Por su lado, en el caso específico de la Constitución boliviana hasta entonces vigente, los derechos relativos a cuestiones sociales y culturales, agrarias y campesinas, se encontraban dispersos, "lo cual impedía tener una visión global del reconocimiento que cada derecho tiene y la protección que debe brindar el Estado". ${ }^{33}$

Los constituyentes que redactaron el "Informe de mayoría" inscribieron su labor en un proceso de ruptura con el pasado neoliberal, y también mostraron las dificultades en la realización de los derechos. Esto no debe llamar la atención, puesto que cinco de los seis constituyentes pertenecían al MAS, protagonista del proceso de cambio. Sin embargo, lo notable es el modo en que se inscribieron en la racionalidad liberal cuando no dudaron en postular que los déficits en la realización de los derechos se explicaban por insuficiencias del poder del Estado, pero no como consecuencia del accionar de otros poderes no estatales. Según entiendo, frente a este pasado del cual hay que distanciarse, la racionalidad que subyace en el modo en que se pensaron los derechos en la Asamblea Constituyente no marca ninguna separación, ninguna distancia con la lógica liberal de concebir los derechos, exclusiva y excluyentemente, frente al poder del Estado.

El apartado octavo del "Informe de mayoría" lleva el título de "Fundamentación de derechos", y en el primer subtítulo, "Disposiciones generales", se lee que el proceso de constitucionalización puede definirse como el esfuerzo por encontrar los mecanismos que garanticen el goce efectivo de "los Derechos Humanos por parte de sus titulares frente al Estado" ${ }^{84}$ En este plano, la Nueva Constitución no marca quiebres con este proceso de constitucionalización, porque diseña un diagrama de derechos que los hace exigibles solamente frente al Estado. En línea con lo anterior, en la fundamentación de los DESG se lee que "[e]l problema de los derechos económicos, sociales y culturales es su realización, dependiente de las posibilidades el Estado". ${ }^{85}$ El desafío no fue rediseñar el sistema de los derechos para que también sean exigibles frente a poderes no estatales, no se intentó avanzar hacia una nueva racionalidad de los derechos, sino que se insistió en

...encontrar en la nueva Constitución mecanismos que aseguren que el Estado cumplirá con su obligación de generar las condiciones que garanticen

83 Ibidem, p. 361. Las itálicas me pertenecen.

84 Ibidem, p. 363. Las itálicas me pertenecen.

85 Ibidem, p. 364. Las itálicas me pertenecen. 
el ejercicio de estos derechos, a través de la legislación, la adopción de políticas y sobre todo, la asignación de presupuesto, a fin de dejar un marco claramente visible de exigibilidad al Estado en caso de omisión. ${ }^{86}$

Aquí se carga la mochila de la exigibilidad de los DESG en el poder del Estado, aunque luego se reconoce, muy tímidamente, que

...estas propuestas expresan la necesidad de adoptar un régimen económico que distribuya la riqueza de forma justa, bajo parámetros sociales que tomen en cuenta el desarrollo equitativo de todos los pueblos que conforman Bolivia y favorezca la adopción de políticas públicas en el ámbito económico, favorable a los pueblos indígenas. ${ }^{87}$

De todos modos, aunque se advierte la necesidad de tener un determinado régimen económico, lo que implica una nueva racionalidad de gobierno con regulaciones y limitaciones no solamente del poder del Estado, sino también del poder que se refugia en bajo un manto de privacidad, en ningún momento hay referencias sobre la exigibilidad de los DESC hacia poderes no estatales, hacia poderes económicos. Es así que luego de enunciarse los déficits en la realización de los DESC, en particular respecto de grupos indígenas y campesinos, se lee que estos derechos garantizan el acceso a medios que permitan tener condiciones de vida dignas y se "plantean a partir de las deficiencias del Estado para garantizar el ejercicio de estos derechos". 88

En la misma línea, en la fundamentación de los derechos de la niñez y de la adolescencia, los constituyentes enunciaron que la finalidad de estos derechos era "buscar la protección integral del Estado, la sociedad y la familia". ${ }^{99} \mathrm{Si}$ bien parecería que el deber de protección no se asienta solamente en el poder del Estado, rápidamente la mochila de los deberes recae sobre su espalda, puesto que tanto respecto de los niños y adolescentes, cuanto de los miembros de la tercera edad, se propone que la nueva Constitución imponga

\footnotetext{
86 Idem. Las itálicas me pertenecen.

87 Idem.

88 Idem. Las itálicas me pertenecen.

89 Ibidem, p. 366. Las itálicas me pertenecen.
} 
...obligaciones del Estado respecto a la adopción de políticas públicas específicas y prioritarias a fin de garantizar a estas personas, en razón de su edad, el acceso, beneficio y ejercicio de sus derechos en general, y de algunos derechos especiales destinados a asegurar su bienestar, su integridad, y su dignidad. ${ }^{90}$

Asimismo, los constituyentes del MAS agregaron que "[e]l Estado tiene la obligación de garantizar, la atención de la salud gratuita para todas las niñas, niños y adolescentes". ${ }^{91}$ En lo relativo a los derechos de las personas con discapacidad, los constituyentes reiteraron que el "Estado tiene la obligación de garantizar y adoptar medidas, para el ejercicio de sus derechos, formuladas como obligaciones del Estado", ${ }^{92}$ y en particular el "Estado debe ofrecer prestaciones de salud". ${ }^{93}$ Por su lado, los derechos ambientales se conceptualizaron como aquellos relacionados con la conservación y protección del ambiente y la lucha contra la contaminación, y aunque todas las personas tienen la obligación de preservar el medio ambiente, "el Estado tiene la obligación de implementar políticas y estrategias para conservar la biodiversidad y mantener los servicios ecológicos". ${ }^{94}$ Finalmente, en el apartado dedicado a los derechos del consumidor, ámbito en el cual los individuos se topan frontalmente con poderes no estatales, los constituyentes volvieron a insistir en que "la protección de los consumidores y usuarios se convierte en un principio básico que obliga al Estado asegurar a los ciudadanos sus derechos y libertades en ese ámbito". ${ }^{95}$

En la línea con los relatos y las representaciones que se encuentran en el Preámbulo, y en el discurso pronunciado por Evo Morales al momento de su promulgación, en el "Informe de mayoría" de la Comisión de Deberes Derechos y Garantías la Nueva Constitución Política del Estado es representada como un quiebre con la racionalidad colonial y neoliberal. De todos modos, hay algo que no se quiebra, que se mantiene tanto en el articulado cuanto en la racionalidad que lo inspiró: los derechos se piensan en referencia al Estado, reactualizando así una racionalidad propia del liberalismo. En el "Informe de mayoría" se traza una conceptualización

\footnotetext{
90 Idem. Las itálicas me pertenecen.

91 Idem. Las itálicas me pertenecen.

92 Ibidem, p. 367. Las itálicas me pertenecen.

93 Idem. Las itálicas me pertenecen.

94 Ibidem, p. 369. Las itálicas me pertenecen.

95 Idem. Las itálicas me pertenecen.
} 
genérica del constitucionalismo y se menciona que uno de los grandes déficits de la consagración de los derechos bajo la racionalidad liberal radica en las insuficiencias del Estado. Sin embargo la racionalidad del nuevo diagrama de derechos no se aparta ni un ápice del sendero trazado por la vieja racionalidad liberal de consagrar los derechos respecto del poder del Estado, pero no de otros poderes no estatales.

\section{Notas Finales}

La perspectiva de la gubernamentalidad propone tener en cuenta al Estado para estudiar las prácticas gubernamentales, pero en lugar de tomar lo que un universal que permite explicarlas, indica que hay que situarlo dentro del marco más amplio del gobierno de los hombres, que se encuentra guiado por una determinada racionalidad. Una de ellas es el liberalismo, que estipula que para gobernar bien es menester limitar las acciones del Estado. Afirmar que el liberalismo es una racionalidad de gobierno implica que el diagrama de derechos humanos no es simple límite a al poder del Estado, sino que es una forma de gobernar.

En este trabajo me ha interesado inscribir la manera en la que García Linera lee la experiencia boliviana como un esfuerzo por establecer una nueva racionalidad de gobierno, dentro de la cual se subraya la urgencia de transformar las estructuras estatales. Entiendo que la racionalidad que inspira la Nueva Constitución Política del Estado puede enmarcarse en esta necesidad de reconvertir el Estado, de avanzar en un Estado plurinacional con pretensiones de intervenir en la economía de modo bien distinto a las recetas liberales y neoliberales. Sin embargo, en el diagrama de los derechos humanos no hay nada "nuevo", puesto que la racionalidad que subyace a su formulación se inscribe dentro de un paradigma liberal. García Linera lee el proceso boliviano a su mejor luz, muestra con notable optimismo el proceso de transición y transformación estatal; pero no dedica algún renglón para reflexionar sobre otra racionalidad que estructure los derechos. Del mismo modo, si analizamos con todo nuestro entusiasmo la Nueva Constitución Política del Estado, es fácil advertir nuevas racionalidades de gobierno que rompen con las del pasado; pero esta novedad se fractura y se transforma en antigüedad cuando se analiza la racionalidad que subyace en el diagrama de los derechos humanos. 
Si es correcto sostener que la formulación liberal de los derechos humanos no son un simple límite al accionar del Estado, sino que son límites inscritos en determinadas formas de gobernarnos, entiendo que resulta urgente preguntarse si tiene sentido mantener una racionalidad liberal de los derechos humanos en procesos que pretenden abandonar el liberalismo. Lo que está en juego, en términos más amplios, es preguntarnos política e intelectualmente si el territorio de los derechos humanos debe quedar en manos de las formulaciones liberales o, al igual que las conceptualizaciones sobre el gobierno y el Estado, pueden transformarse en un territorio en disputa.

\section{BIBLIOGRAFÍA}

Burchell, Graham, "Peculiar Interests: Civil Society and Governing the System of Natural Liberty", en BuRchelL, Graham et al. (eds.), The Foucault Effect. Studies in Governmentality, Chicago, Chicago University Press, 1991.

CAstro, Edgardo, "Categorías de la filosofía política contemporánea: gubernamentalidad y soberanía”, Revista de Filosofia y Teoría Política, La Plata, núm. 35, 2004.

Dean, Mitchell, Governmentality. Power and Rule in Modern Society, Londres, Sage, 1999.

ENGELS, Friedrich, "Introducción”, en MARX, Karl, La guerra civil en Francia, Madrid, Fundación Federico Engels, 2007.

Hindess, Barry, Discourses of Power: From Hobbes to Foucault, Oxford, Blackwell, 1996.

FOUCAUlt, Michel, "Il faut défendre la société", Cours au Collège de France (1975-1976), París, Gallimard-Seuil, 1997.

_- "La technologie politique des individus", en Dits et écrits II, Paris, Gallimard, núm. 364, 2001.

, Sécurité, territoire, population. Cours au Collège de France (1977-1978), París, Gallimard-Seuil, 2004.

—, Naissance de la biopolitique. Cours au Collège de France (1978-1979), París, Gallimard-Seuil, 2004.

GARcía LinerA, Álvaro, "Lucha por el poder en Bolivia”, La potencia plebeya, Bogotá, Siglo del Hombre Editores-Clacso, 2009. 
, Conferencia "La construcción del Estado", Buenos Aires, Facultad de Ciencias Sociales de la Universidad de Buenos Aires, 2010.

-, "El Estado en transición. Bloque de poder y punto de bifurcación", en García Linera, Álvaro et al., El Estado. Campo de lucha, La Paz, Muela del Diablo-Comuna-Clacso, 2010.

— Las tensiones creativas de la revolución. La quinta fase del proceso de cambio, La Paz, Vicepresidencia del Estado Plurinacional, 2011. - Geopolítica de la Amazonia. Poder hacendal-patrimonial y acumulación capitalista, La Paz, Vicepresidencia del Estado Plurinacional, 2012. -, "Estado, democracia y socialismo", Socialismo comunitario. Un horizonte de época, La Paz, Vicepresidencia del Estado Plurinacional, 2015. , "A la izquierda europea", Socialismo comunitario. Un horizonte de época, La Paz, Vicepresidencia del Estado Plurinacional, 2015.

Gargarella, Roberto, La justicia frente al gobierno, Buenos Aires, Ariel, 1996.

GORDON, Gollin, "Governmental Rationality: An Introduction", en BuRCHELL, Graham et al. (eds.), The Foucault Effect. Studies in Governmentality, Chicago, Chicago University Press, 1991.

GRAMSCI, Antonio, "El problema de la dirección política en la formación y desarrollo de la nación y del Estado moderno en Italia", Cuadernos de la Cárcel 5, México, Ediciones Era-Benemérita Universidad Autónoma de Puebla, 1999.

Gros, Frédéric, Michel Foucault, París, Presses Universitaires de France, 1996.

HAYEK, Friedrich, Camino de servidumbre, Madrid, Alianza.

Hindess, Barry, "Liberalism, Socialism and Democracy: Variations on a Governmental Theme", en BARRY, Andrew et al. (eds.), Foucault and Political Reason. Liberalism, Neo-Liberalism and Rationalities of Government, Chicago, Chicago University Press, 1996.

, "Informe de mayoría de la Comisión de Deberes, Derechos y Garantías", Enciclopedia Histórica Documental del Proceso Constituyente Boliviano, vol. III, La Paz, Vicepresidencia del Estado Plurinacional, 2012.

LAZZARATO, Maurizio, Biopolítica. Estrategias de gestión y agenciamientos de creación, Bogotá, Universidad Central-IESCO-Se Cauto, 2007.

Lemke, Thomas, "Foucault, Governmentality, and Critique", Rethinking Marxism: A Journal of Economics, Culture \& Society, vol. 14, núm. 3, 2002. 
Esta revista forma parte del acervo de la Biblioteca Jurídica Virtual del Instituto de Investigaciones Jurídicas de la UNAM

LENIN, Vladimir I., El Estado y la revolución, Madrid, Fundación Federico Engels, 2009.

MaLeTte, Sébastien, La gouvernementalité chez Michel Foucault, Québec, Université Laval, 2006.

MARINIS, Pablo de, "Gobierno, gubernamentalidad, Foucault y los anglofoucaultianos ( $\mathrm{O}$ un ensayo sobre la racionalidad política del neoliberalismo)", en TORRe, Ramón y García Salgas, Fernando (eds.), Globalización, riesgo, reflexividad, Madrid, Centro de Investigaciones Sociológicas, 1999.

MARX, Karl, La guerra civil en Francia, Madrid, Fundación Federico Engels, 2007. Manifiesto Comunista, Madrid, Debate, 1998.

Miliband, Ralph, Marxismo y política, Madrid, Siglo XXI, 1978.

Morales Ayma, Evo, "Palabras del presidente del Estado Plurinacional de Bolivia, Evo Morales Ayma, en la promulgación de la nueva Constitución Política del Estado", Enciclopedia Histórica Documental del Proceso Constituyente Boliviano, La Paz, Vicepresidencia del Estado Plurinacional, 2012.

O’Malley, Pat, "Experimentos en gobierno. Analíticas gubernamentales y conocimiento estratégico del riesgo", Revista Argentina de Sociología, Buenos Aires, núm. 8, 2007.

PoulantZas, Nicos, Estado, poder y socialismo, Madrid, Siglo XXI, 1978.

Rose, Nikolas, Powers of Freedom. Reframing Political Thought, Cambridge, Cambridge University Press, 1999.

- y MiLLER, Peter, "Governing Economic Life", Economy and Society, vol. 19, núm. 1, 1990.

, "Political Power beyond the State: Problematics of Government", The British Fournal of Sociology, Londres, vol. 43, núm. 2, 1992.

Sousa Santos, Boaventura de, Refundación del Estado en América Latina, Lima, Instituto Internacional de Derecho y Sociedad-Programa Democracia y Transformación Global, 2010.

, "Refundación del Estado en Bolivia", en AA. VV., Pensando el mundo desde Bolivia, La Paz, Vicepresidencia del Estado Plurinacional, 2012.

VALverde, Mariana y LEVI, Ron, "Gobernando la comunidad a través de la comunidad", Delito y Sociedad. Revista de Ciencias Sociales, Buenos Aires, Santa Fe, núm. 22, 2006. 